Open Access

\title{
Innovation and service outsourcing: an empirical analysis based on data from Tunisian firms
}

Hanen Sdiri and Mohamed Ayadi

\author{
* Correspondence: \\ sdirihanen@gmail.com \\ UAQUAP-Tunis Higher Institute of \\ Management, 41 Rue de la liberté, \\ 2000 Le Bardo, Tunis, Tunisia
}

\begin{abstract}
Recently, outsourcing services has been an important component of the organizational strategy of service firms. However, most research studies mainly focus on analyzing the determining factors of outsourcing at the expense of its structural effects. The aim of this paper is to examine the extent to which outsourcing relationships can be a source of service innovation by using a sample of 108 Tunisian service firms. Specifically, we are interested in the domestic outsourcing of auxiliary activities. Our results support the evidence of positive effects of outsourcing service activities on the capacity of innovation. This suggests that outsourcing allows Tunisian service firms to create value, increase flexibility and improve the quality of their services.

Keywords: Innovation, Outsourcing, Services sector

JEL Classification: D23, L21, L80, O31, O32
\end{abstract}

\section{Background}

In a competitive context and in an uncertain economic environment, the access to the best available technologies and the creation of value -among others- are two objectives that a service firm cannot always reach in-house by its own means. It is for this reason that many firms have resorted to new ways of managing the relationships with their environment. Indeed, the most frequently used organizational strategies are establishing new forms of collaboration with research centers or clients, using new methods of integration with suppliers and outsourcing an organization's own services (OCDE 2005). Among these forms, the present paper focuses mainly on outsourcing as it represents an important potential source for innovation. Outsourcing allows the access to the specialized technological competences of the external organizations as well as sustaining the research and development (R\&D) activities more effectively in order to develop new products/services (i.e., by reducing costs, shrinking the time to market, increasing flexibility and enhancing quality) (Quinn 2000; Espino-Rodríguez and Padrón-Robaina 2004 and Carson 2007).

Therefore, after affecting the industrial activities, the outsourcing approach has now an impact on the service sector. Indeed, this approach has incremented with the development of technology-intensive sectors. Outsourcing is no longer new as its forms have been well developed in the European countries. According to the Outsourcing

(c) 2016 Sdiri and Ayadi. Open Access This article is distributed under the terms of the Creative Commons Attribution 4.0 International License (http://creativecommons.org/licenses/by/4.0/), which permits unrestricted use, distribution, and reproduction in any medium, provided you give appropriate credit to the original author(s) and the source, provide a link to the Creative Commons license, and indicate if changes were made. 
Barometer published by Young (2010), 70 \% of European firms resort to outsourcing. In the Tunisian context, for instance, outsourcing services has recently witnessed an outstanding expansion with $77 \%$ of Tunisian firms resorting to outsourcing (Outsourcing Barometer 2006). Engardio and Arndt (2006) indicate that 18.4 billion dollars of trade in the information technologies and 11.4 billion dollars of company services were outsourced, representing $10 \%$ of the potential market. In addition, the OECD 2005 report shows that the total number of positions that can be affected by outsourcing accounts for about $20 \%$ of the employment in certain countries.

Rare are the empirical studies that analyze the relationship between outsourcing and performance, and these are restricted to the motivations that incentivize firms to outsource. Girma and Görg (2004) have shown that outsourcing is positively linked to labor productivity and total factor productivity. Also, Maskell et al. (2007) have concluded that outsourcing can offer firms not only lower costs but also better quality and access to innovation. Yet, this kind of analysis has never included emerging countries, Tunisia in particular. The present paper aims at analyzing then the effect of the domestic outsourcing of the auxiliary activities on the development of innovations. This work is an attempt at proving the extent to which the domestic outsourcing of service activities leads to lower costs, higher production flexibility and better service quality for $\mathrm{Tu}$ nisian service firms.

The remainder of the paper is organized as follows. 'Outsourcing service activities: related literature' section outlines a brief literature review. The 'Methods' section deals with the data, the variables measure and the models' economic specification. 'Results and discussion'. section analyzes the main econometric results. The last section is the 'Conclusions' section.

\section{Outsourcing service activities: related literature}

\section{Context and definitions}

Outsourcing implies the transfer of goods and services that were previously carried inhouse to an external and more specialized provider (Domberger 1998). Nowadays, reinforcing the outsourcing of industrial production arouses growing concerns. This tendency has long existed, but it seems to become more marked and to expand beyond the manufacturing sector to encompass that of services. In the same context, Lankford and Parsa (1999) define outsourcing as the fact of providing services to sources that are external to the firm. Thus, outsourcing means the allocation or reallocation of service activities of an internal source to an external one (Schniederjans et al. 2005).

The topic of outsourcing is a key concept for services and their innovation (Gallouj and Windrum 2009). In this setting, many authors have closely examined the determining factors of taking the decision to outsource. Bartel et al. (2008) have shown that outsourcing activities are more advantageous for a service firm when the technological changes are evolving rapidly. Windrum et al. (2009) have focused on the paradox of outsourcing productivity by examining the links between total outsourcing and operational innovation. They have shown that, on the short term, the 'outsourcing' firms are willing to decrease their marginal production costs. However, Espino-Rodríguez and Padrón-Robaina (2004) have revealed that outsourcing has a great potential not only through reducing costs but also in terms of other operational objectives such as enhancing quality and ensuring 
production flexibility. Miozzo and Soete (2001) show that the services suppliers, which are historically internalized in large corporations (accounting, advertising, distribution, etc), were outsourced during the last decades mainly in the developed economies.

\section{Outsourcing motivations}

Outsourcing is integrated to the essential elements of firms' strategy. Firms are constantly searching an organization which provides high service at lower cost. Therefore, diminishing costs represent the main factor urging firms to outsource (Pierre-Paul 2006). Indeed, outsourcing offers the advantage of transparency and allows better expenditure management. It is considered as a means of re-centring the company activity on its primary competence while allocating its secondary tasks to more specialized providers in order to generate higher added value. As they focus on their primary task, firms provide better solutions through constant technological watch and upgrading of labor methods. The multiplicity and diversity of customers continually enrich firms' know-how and improve the efficiency of their operating methods. Furthermore, competition puts pressure on firms in a bid to seek a standing efficiency. Indeed, the globalization of economy, the shortening of the products life cycle as well as the increase of uncertainties oblige companies to delegate the operations that are doomed to have lower added value for their activities to external providers. In other words, outsourcing enables companies to optimize their operational competitiveness and to adapt to the frequent changes and the constant evolution of their environment.

\section{Methods}

Data and variables measure

Data

In this paper, the data used are from a survey conducted on Tunisian service firms. ${ }^{1}$ This survey belongs to the modified version of the third Community Innovation Survey (CIS) 3 and to the second European innovation survey 1997. However, to account for the role of integrating information technologies on the firms' performance, the 2002 survey on information and communication technologies (henceforth ICTs) and electronic trade has also been referred to.

The questionnaire ${ }^{2}$ used for the survey offers a wide range of data. Apart from the general information about the firm, the questionnaire is built on three major sections: outsourcing, innovation and the use of the ICT. First of all, the surveyed firms were asked about their firm's operational structure. More precisely, they were interviewed about outsourcing activities which were previously realized in-house. Secondly, the survey also questions whether the firm has introduced any innovations during the 2005-2007 period. Finally, a section is devoted to exploring the impact of integrating ICTs within firms. The respondents were asked to specify whether the firm has resorted to any new technologies during 2005-2007 and the extent to which these technologies contributed to sales growth.

Among the 200 questionnaires directly delivered to the firms, only 108 workable responses were obtained, that is to say a $54.5 \%$ response rate. Yet, these observations are not adequately weighted. Nonetheless, to ensure the representativeness of the sample, this latter was stratified by workforce bracket using the NTA ${ }^{3}$ code of the National Institute of the Statistics (seven classes by number of employees: 1-6, 7-9, 10-19, 20-49, 50-90, 100-199, 200 
and more). To each class, a weight was attributed, representing this bracket's weight at the national level, so as to obtain a more representative sample of the service firms in Tunisia.

Table 1 summarizes the determining factors of this operation. It shows that $85.18 \%$ of the surveyed firms declared having resorted to outsourcing during 2005-2007. If the size of firms, in terms of the number of employees, is taken into account, it is noticed that the small firms outsource more than the large ones $(22.82 \%)$. Thus, this table shows that $22.22 \%$ of the innovating firms declare having outsourced a part of their functions during the survey period.

The survey provides information about the sector where a firm operates. We have classified the firms according to three main activities. ${ }^{4}$ First, ACT1 incarnates the enterprises that belong to sections $\mathrm{H}$ (transportation and storage), $\mathrm{N}$ (administrative and support service activities) and $S$ (other service activities). Second, ACT2 incorporates the enterprises that are affiliated to sections $M$ (professional, scientific and technical activities) and K (financial and insurance activities). Finally, ACT 3 consists of the enterprises that are in section $J$ (Information and communication). Using the data collected from this survey, we also present the distribution of firms by business sector. We show that the largest number of companies is located in ACT3 (52.78\%), followed by companies operating in ACT2 (32.41 \%) and $14.81 \%$ are in ACT1 (see Appendix 1).

\section{Variables measure}

\section{Innovation}

The literature includes many indicators to measure the output of innovation. Some use the patent portfolio (Mairesse and Mohnen 2003) while others use the R\&D expenses as innovation indicators. This paper uses variables showing the main advantages urging firms to outsource. The choice is justified by the fact that outsourcing represents an important potential source of innovation, according to Quinn (2000) and Espino-Rodríguez and Padrón-Robaina (2004). To measure these advantages, an ordinal 5-point scale is used, showing the degree of importance that firms attribute to the following objectives: reducing costs (red_cout), enhancing services quality (qua_ser) and increasing flexibility (flex_pro).

The innovation output (inserv) is also measured by a binary variable taking the value 1 if the firm has innovated during the last 3 years and the value 0 otherwise. More precisely, the focus is on information stipulating whether a firm has already implemented any product or any new procedure or has even considerably improved any new

Table 1 Distribution and weighting of the sample firms

\begin{tabular}{|c|c|c|c|c|c|c|c|c|}
\hline \multirow[t]{2}{*}{ Size } & \multicolumn{4}{|l|}{ Total } & \multicolumn{2}{|c|}{ Outsourcing } & \multicolumn{2}{|c|}{ Innovation } \\
\hline & Number of respondents & INS' firms & Corrected weight & $(\%)$ & Number & $(\%)$ & Number & $(\%)$ \\
\hline $1-6$ & 23 & 12,649 & 549.95 & 21.30 & 21 & 22.82 & 16 & 22.22 \\
\hline $7-9$ & 17 & 785 & 46.17 & 15.74 & 14 & 15.21 & 9 & 12.5 \\
\hline 10-19 & 18 & 713 & 39.61 & 16.67 & 13 & 14.13 & 11 & 15.27 \\
\hline $20-49$ & 13 & 509 & 93.15 & 12.04 & 11 & 11.95 & 10 & 13.88 \\
\hline $50-90$ & 10 & 230 & 23 & 9.26 & 8 & 8.69 & 6 & 8.33 \\
\hline $100-199$ & 10 & 167 & 16.7 & 9.26 & 9 & 9.78 & 6 & 8.33 \\
\hline$\geq 200$ & 17 & 215 & 12.64 & 15.74 & 16 & 17.39 & 14 & 19.44 \\
\hline Total & 108 & 15268 & 781.24 & 100 & 92 & 100 & 72 & 100 \\
\hline
\end{tabular}


marketing or operating method in its practices. In fact, we have enclosed with the questionnaire a supplementary explanatory guide where we have defined all the technical terms including service innovation. This latter has been taken from the third Community Innovation Survey (CIS3). ${ }^{5}$

\section{Outsourcing}

Prior empirical studies have used different indicators in order to measure outsourcing. Gilley and Rasheed (2000) have measured outsourcing by the share of the total value of the firm's outsourced activities. Following Cusmano et al. (2009), we define outsourcing (exter) by a binary variable showing whether a firm has delegated a given task to a specialist outside the firm between 2005 and 2007. We have essentially focused on the outsourcing of the auxiliary activities that are not at the core of the main activity of the enterprise. We have asked the following question: 'During the three years 2005 to 2007, did your enterprise outsource auxiliary tasks?'

Use of ICTs

These are considered as sources of innovation in services. To measure this variable, some authors use the investments in ICT as an appropriate indicator (Gago and Rubalcaba 2007). In this paper, however, as there are nominal variables in the survey, the factorial analysis is the most suitable method in order to process data and analyze the correlations existing between the different items. This method aims at summarizing the huge amount of data. Therefore, a first multiple correspondence analysis is conducted (MCA) on the items relative to the use of ICTs: 'local Internet network,' 'Internet,' Intranet,' 'Exchange of computerized data on Internet', and 'Web site'. This MCA allows the retaining of only one factor, called 'tic'. The MCA results on these items (Table 2) show that, according to the precision of the Kaiser-MeyerOlkin measure of sampling adequacy (0.753) as well as the significance of the Bartlett Sphericity test, the items are so correlated that they are factorized $\left(\chi^{2}=113.45\right)$. Thus, the retained dimension presents a good reliability given by the Crombach $\alpha$ value (0.721).

\section{Relationship with clients}

Studies dealing with the innovation in services have focused on the services-specific characteristics that directly affect the development of innovations, such as the interaction between the service provider and the client. In this paper, the interaction with clients is measured by a constructed variable generated from the principal components analysis (PCA) so as to

Table 2 Matrix of components (use of ICTS)

\begin{tabular}{ll}
\hline Items & Dimension \\
\hline Local internet network & 0.729 \\
Internet & 0.499 \\
Intranet & 0.756 \\
Exchange of computerized data Internet & 0.736 \\
Web site (their own or shared) & 0.756 \\
Cronbach's alpha & 0.721 \\
Kaiser-Meyer-Olkin (KMO) & 0.753 \\
Eigenvalue & 2.466 \\
\% variance & 49.313 \\
Bartlett sphericity test chi square & 113.45 \\
df & 10 \\
sig & 0.000 \\
\hline
\end{tabular}


summarize the huge amount of data from the study of items that show the advantages of online business. These items are 'reducing costs', 'increasing the number of clients', 'better coordination with clients and suppliers', and 'shrinking the time to market'. The PCA results on these items and according to the statistic criterion of eigenvalues associated to the axis $(\lambda>1 / 4)$ show that only one dimension called 'intclt' can be retained (Table 3). The reliability of this measure is confirmed by the Bartlett sphericity test $\left(\chi^{2}=435.416\right)$ and by the Kaiser-Meyer-Olkin (KMO) test (0.846).

Another variable is also used to show the impact of using Internet on the growth of firms' sales (inter). For this reason, one possibility is to ask firms to indicate whether their sales have changed after using the internet. More precisely, an ordered dichotomic variable is used to show whether sales have increased, decreased or stabilized after using Internet as a marketing tool.

\section{Organizing $R \& D$ activities}

Although the internal R\&D activities are necessary to attract the external competences (Cohen and Levinthal 1990), the extramural $R \& D$, if correctly planned and implemented, can help companies further innovate and hence improve their performances (Caudy 2001). Similar to Huang et al. (2009), a binary variable is used showing whether the company has acquired any external R\&D services between 2005 and 2007 as a measure of organizing R\&D activities $\left(r d_{-} e x\right)$.

\section{Concentration}

Many studies have analyzed the role of the innovating corporate spatial concentration in particular territories (Cusmano et al. 2009 and Uzunidis 2010). These territories can be high-tech park that include companies, research centers or universities. In this paper, to account for the impact of concentration on firms, a binary variable is used showing whether the respondent firm is located or not in the ICT high-tech park (concen). If a firm is located there, it generates synergy effects by developing interaction relationships, and it then benefits from the experiences and the competences of the neighboring firms.

National cooperation

It is widely known that cooperation is an important factor favoring innovation in services (Sdiri and Ayadi 2014). The national cooperation variable (cooperNat) is introduced as a binary variable showing whether a firm has signed, during the 2005-2007 period, any cooperation contracts with other companies in the same field, with

Table 3 Matrix of components (interaction with clients)

\begin{tabular}{ll}
\hline Items & Dimension \\
\hline Reducing costs & 0.919 \\
Increasing the number of clients & 0.94 \\
Better coordination with clients and suppliers & 0.938 \\
Shrinking the time to market & 0.936 \\
Cronbach's alpha & 0.951 \\
Kaiser-Meyer-Olkin (KMO) & 0.846 \\
Eigenvalue & 3.485 \\
\% variance & 87.143 \\
Bartlett Sphericity Test chi square & 435.416 \\
$d f$ & 6 \\
sig & 0.000 \\
\hline
\end{tabular}


consumers, with equipment and software suppliers, with competitors, with research and counseling firms and with universities situated in Tunisia. This variable is introduced in the models to show the extent to which the external relationships enable the development of innovations.

\section{Qualification and age of the firm}

In this paper, the level of qualification (Qual) is measured by the number of qualified ${ }^{6} \mathrm{em}$ ployees divided by the total number of the firm's employees. The age of the firm (age) is determined by the date of its foundation. More precisely, this measure represents the experiences as well as the competences accumulated during the firm's history. Thus, the age is a source for creating innovations and provides more and more absorptive capacities.

\section{Models' economic specification}

\section{Ordered probit model}

The answers to the different motivations that allow the Tunisian service firms to outsource a part of their activities are classified according to a 6-point scale. The value zero indicates that the firm gives 'no importance' to the different listed motivations while the value 5 means that it accords a 'very large importance' to them. The discrete and ordered structure of this dependent variable allows the use of ordered response models. The values taken by the multinomial variable $\left(y_{i}=0,1,2,3,4,5\right)$ are grouped into intervals where we find only one continuous unobservable latent variable $y_{i}^{*}$. This kind of model assumes that the values are identical for all observations. Indeed, the level of $y^{*}$ is parameterized by the threshold parameters $c_{j}$, and a constant is therefore not introduced in the linear model. This model is written as follows ${ }^{7}$

$$
y_{i}=\left\{\begin{array}{l}
0 \text { if } y_{i}^{*}<c_{1} \\
1 \quad \text { if } c_{1} \leq y_{i}^{*}<c_{2} \quad \forall i=1, \ldots 108 \\
\ldots \\
5 \text { if } y_{i}^{*}>c_{5}
\end{array}\right.
$$

The threshold parameters $c_{j}$ are in ascending order $\left(c_{j+1} \geq c_{j}\right)$ where the variable $y_{i}^{*}$ is defined by:

$$
y_{i}^{*}=x_{i} \beta^{\prime}+\varepsilon_{i} \quad \varepsilon_{i}^{\sim} N[0,1]
$$

where $x_{i}$ represents the vector of the explanatory variables and $\varepsilon_{i}$ is an random error term assumed to have a normal distribution. The parameters $\beta$ and $c_{j}, j=1, \ldots 5$ are estimated using the ordered probit model by maximizing the log-likelihood function. The implied probabilities are obtained by

$$
\begin{aligned}
& P_{i j}=\operatorname{Pr}\left(y_{i}=j\right) \forall j=0, \ldots, 5 \\
& \text { where; } \quad \operatorname{Pr}\left(y_{i}=j\right)=\operatorname{Pr}\left(\alpha_{j}<x_{i} \beta^{\prime}+\varepsilon_{i} \leq \alpha_{j+1}\right) \\
& =\operatorname{Pr}\left(\alpha_{j}<x_{i} \beta^{\prime}+\varepsilon_{i} \leq \alpha_{j+1}\right) \\
& =\operatorname{Pr}\left(\alpha_{j}-x_{i} \beta^{\prime}<\varepsilon_{i} \leq \alpha_{j+1}-x_{i} \beta^{\prime}\right) \\
& =F\left(\alpha_{j+1}-x_{i} \beta^{\prime}\right)-F\left(\alpha_{j}-x_{i} \beta^{\prime}\right)
\end{aligned}
$$

where $F($.$) denotes the standard normal cumulative distribution function.$ 


\section{Ordered probit model with selection}

In the previous section, the contribution of outsourcing to the development of service innovation has been analyzed. This analysis was achieved on the total sample of firms. Nonetheless, it could not be reasonable to admit that the innovating and noninnovating firms are randomly selected from a total population of firms. If that were the case, we would fall into a selection bias problem. Consequently, the maximum likelihood estimator can be irrelevant since it does not account for the selection effects operating by the non-observables in the model.

Many methods can be used to control this bias, namely Heckman (1979)'s two-stage method. Yet, this procedure cannot be applied in the present case. Indeed, Heckman's selection models apply to continuous dependant variables in the interest equation. In this paper, we hold a multinomial ordered data. For that reason, a De Luca and Perotti (2010) ${ }^{8}$ ordered probit model is used, taking into account the selection bias problem. This model includes two equations, one for the binary indicator of the sample selection (the selection equation) and another for the ordered variable. Accordingly, the observed variable $y$ is determined by another variable which in turn determines whether the innovating effect exists or not (called $\left.z^{*}\right)$. The variable $z^{*}$ can have the null value if the firm does not innovate and 1 if the firm innovates. Therefore, the variable $y$ is observed only if the selection condition $(z=1)$ is met. The model is given as follows:

$$
\begin{aligned}
& y *=\beta^{\prime} x+\varepsilon, \\
& z *=\alpha^{\prime} v+u, \quad \text { où } \varepsilon, u \approx N\left(0,0, \sigma_{\varepsilon}^{2}, \rho\right)
\end{aligned}
$$

The variables $z^{*}$ and $y^{*}$ are not observed. On the other hand, the variable $z$ is observed and given by:

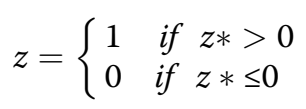

\section{Results and discussion}

\section{Empirical validation}

Table 4 presents the means, the standard deviations of each variable as well as the correlation matrix between variables used in the models. The table also provides the test

Table 4 The correlation matrix between variables

\begin{tabular}{lllllllllllll}
\hline Variables & Mean & SD & VIF & $(1)$ & $(2)$ & (3) & (4) & (5) & (6) & (7) & (8) & (9) \\
\hline (1) exter & 0.85 & 0.35 & 1.12 & 1 & & & & & & & & \\
(2) intclt & $-4.35 \mathrm{e}-09$ & 1 & 1.57 & 0.10 & 1 & & & & & & \\
(3) tic & $1.90 \mathrm{e}-08$ & 1 & 1.47 & -0.06 & 0.11 & 1 & & & & & \\
(4) inter & 1.49 & 0.50 & 1.76 & 0.04 & $-0.51^{*}$ & $-0.37^{*}$ & 1 & & & & \\
(5) cooperNat & 0.5 & 0.5 & 1.12 & 0.10 & 0.10 & -0.01 & $-0.20^{*}$ & 1 & & & \\
(6) age & 12.93 & 19.25 & 1.36 & 0.15 & $-0.20^{*}$ & 0.14 & 0.04 & 0.01 & 1 & & & \\
(7) concen & 0.24 & 0.42 & 1.16 & -0.07 & 0.12 & $0.20^{*}$ & -0.16 & 0.12 & -0.17 & 1 & \\
(8) rd_ex & 0.36 & 0.48 & 1.17 & 0.09 & 0.15 & $0.27^{*}$ & -0.15 & $0.21^{*}$ & -0.03 & 0.07 & 1 \\
(9) Qual & 0.74 & 0.24 & 1.47 & $-0.24^{*}$ & 0.11 & $0.27^{*}$ & $-0.20^{*}$ & -0.08 & $-0.39^{*}$ & $0.31^{*}$ & 0.04 & 1 \\
\hline
\end{tabular}

*Significance at the level of $5 \%$ 
based on each coefficient's variance inflation factor (VIF). More precisely, it is noticed that the mean VIF is about 1.36 inferior to 6 and that VIF of each variable is inferior to 10. According to this result, it is proved that there is no multicollinearity problem between the explanatory variables used in these models. Consequently, the heteroscedasticity problem was solved using White's correction. Hence, to check that some variables seem endogenous, Hausman's specification test was used as it allows the detection of any endogeneity bias. Indeed, the test confirms the absence of the endogeneity problem. This means that the residuals obtained from the equations of the first step are not correlated to the measure of innovation, which refutes the endogeneity hypothesis.

The estimations relative to the models with or without selection lead to a quality of adjustment, given by the Wald test $\chi^{2}$ and the likelihood ratio test LR, that is acceptable at $1 \%$. On the other hand, to choose the suitable model, the Akaike information criterion is used (Akaike 1974) AIC $=-2 \mathrm{LL}+2 k$ as well as the Bayesien information criterion (Schwarz 1978) $\mathrm{BIC}=-2 \mathrm{LL}+k \log (n)$, where $k$ is the number of parameters, $\mathrm{LL}$ is the maximum loglikelihood and $n$ the number of observations. As indicated in Table 5 below, the ordered probit model with selection is the most relevant except for the case the 'qua_ser' dimension.

\section{Impact of outsourcing and other innovation explaining variables}

Based on the results of Table 6, it is noticed that the interest variable (exter) of the model without selection has a positive coefficient and is statistically significant at $1 \%$, confirming the hypothesis that outsourcing services is positively correlated to innovation. This result suggests that resorting to outsourcing permits the Tunisian service firms to create value (by reducing costs). Outsourcing abates the marginal production costs and increases profits by producing higher stimuli for innovation (Glass and Saggi 2001). Moreover, it allows increasing flexibility and enhancing the quality of the firms' services. Likewise, the results obtained from the second model (with selection) confirm that outsourcing remains significant also at the level of $1 \%$. The results of the ordered probit model with selection justify, in some way, the conclusions drawn from the first model. This means that the outsourcing strategy is beneficial for the Tunisian service firms in terms of innovation. A similar effect was noticed by Cantone and Testa (2009). This result unveils that the outsourcing relationships contribute to the development of the firms'organizational capacities. In fact, the motivations impelling firms to outsource are not limited to diminishing costs, but have rather changed to include other exploitation-related objectives such as quality and flexibility (Ehie 2001; Kremic et al. 2006).

Table 5 Comparison of models

\begin{tabular}{|c|c|c|c|c|c|c|}
\hline & \multicolumn{3}{|c|}{ Standard ordered probit } & \multicolumn{3}{|c|}{ Ordered probit with selection } \\
\hline & (1) red_cout & (2) qua_ser & (3) flex_pro & (1) red_cout & (2) qua_ser & (3) flex_pro \\
\hline LR test & 7118.654 & 9766.78 & 5960.21 & 4529.506 & 1581.3 & 3691.124 \\
\hline Prob $>x^{2}$ & $(0.000)$ & $(0.000)$ & $(0.000)$ & $(0.000)$ & $(0.000)$ & $(0.000)$ \\
\hline Wald $x_{7}^{2}$ & 35.385 & 41.49 & 30.82 & 35.26 & 44.821 & 27.773 \\
\hline Prob $>x^{2}$ & $(0.000)$ & $(0.000)$ & $(0.000)$ & $(0.000)$ & $(0.000)$ & $(0.000)$ \\
\hline $\mathrm{AIC}$ & $42,663.3$ & $31,940.35^{a}$ & $45,414.32$ & $37,893.89^{a}$ & $35,921.03$ & $41,897.73^{\mathrm{a}}$ \\
\hline $\mathrm{BIC}$ & $42,695.03$ & $31,972.08^{a}$ & $45,446.05$ & $37,946^{\mathrm{a}}$ & $35,973.14$ & $41,949.83^{\mathrm{a}}$ \\
\hline
\end{tabular}

${ }^{\text {a }}$ hows the relevant model 
Table 6 Standard ordered probit versus ordered probit with selection

\begin{tabular}{|c|c|c|c|c|c|c|c|c|c|c|c|c|}
\hline \multirow[t]{3}{*}{ Variables } & \multicolumn{6}{|c|}{ Standard ordered probit (M1) } & \multicolumn{6}{|c|}{ Ordered probit with selection (M2) } \\
\hline & \multicolumn{2}{|l|}{ red_cout } & \multicolumn{2}{|l|}{ qua_ser } & \multicolumn{2}{|l|}{ flex_pro } & \multicolumn{2}{|l|}{ red_cout } & \multicolumn{2}{|l|}{ qua_ser } & \multicolumn{2}{|l|}{ flex_pro } \\
\hline & Coef. & RSE & Coef. & RSE & $\overline{\text { Coef. }}$ & RSE & $\overline{\text { Coef. }}$ & RSE & Coef. & RSE & Coef. & RSE \\
\hline Outsourcing (exter) & $2.884^{* * *}$ & $(0.609)$ & $2.306^{* * *}$ & $(0.495)$ & $1.943^{* * *}$ & $(0.494)$ & $2.936^{* * *}$ & $(0.693)$ & $1.998^{* * *}$ & $(0.466)$ & $1.469^{* * *}$ & $(0.519)$ \\
\hline Interaction with clients (intclt) & -0.037 & $(0.294)$ & $0.618^{* *}$ & $(0.313)$ & 0.226 & $(0.252)$ & $0.527^{* *}$ & $(0.245)$ & $0.968 * * *$ & $(0.308)$ & $0.643 * *$ & $(0.258)$ \\
\hline Use of ICTs (tic) & -0.138 & $(0.178)$ & $-0.868^{* * *}$ & $(0.313)$ & -0.218 & $(0.171)$ & -0.548 & $(0.358)$ & -0.555 & $(0.390)$ & $-0.677 * *$ & $(0.296)$ \\
\hline Internet business (inter) & -0.011 & $(0.580)$ & 0.407 & $(0.535)$ & -0.204 & $(0.606)$ & 0.217 & $(0.541)$ & 0.641 & $(0.541)$ & 0.119 & $(0.564)$ \\
\hline National cooperation (cooperNat) & 0.078 & $(0.355)$ & 0.186 & $(0.353)$ & -0.406 & $(0.381)$ & -0.390 & $(0.274)$ & -0.011 & $(0.326)$ & $-0.749 * *$ & $(0.356)$ \\
\hline Age of the firm (age) & 0.018 & $(0.022)$ & 0.004 & $(0.013)$ & 0.011 & $(0.013)$ & $0.035 *$ & $(0.019)$ & 0.012 & $(0.010)$ & 0.015 & $(0.012)$ \\
\hline Concentration (concen) & $0.834^{* *}$ & $(0.399)$ & $0.769^{*}$ & $(0.435)$ & $1.594^{* * *}$ & $(0.479)$ & $0.969 * *$ & $(0.447)$ & 0.593 & $(0.430)$ & $1.510 * * *$ & $(0.508)$ \\
\hline Outsourcing (exter) & & & & & & & $1.370 * *$ & $(0.625)$ & $1.390 * *$ & $(0.673)$ & $1.322 * *$ & $(0.627)$ \\
\hline Interaction with clients (intclt) & & & & & & & 0.221 & $(0.309)$ & 0.318 & $(0.300)$ & 0.174 & $(0.280)$ \\
\hline Use of ICTs (tic) & & & & & & & $0.657^{* *}$ & $(0.264)$ & $0.842 * * *$ & $(0.312)$ & $0.615^{* *}$ & $(0.259)$ \\
\hline Internet business (inter) & & & & & & & 0.321 & $(0.607)$ & 0.597 & $(0.570)$ & 0.058 & $(0.484)$ \\
\hline Extramural R\&D (rd_ex) & & & & & & & $1.575^{* * *}$ & $(0.572)$ & $1.123 *$ & $(0.640)$ & $1.117^{* *}$ & $(0.544)$ \\
\hline Qualification (Qual) & & & & & & & $1.667 * *$ & $(0.777)$ & $1.890 * *$ & $(0.741)$ & $2.238 * * *$ & (0.823) \\
\hline $\mathrm{cl}$ & 1.347 & $(0.969)$ & 1.243 & $(0.928)$ & 0.322 & $(1.029)$ & $1.627 *$ & $(0.900)$ & 1.426 & $(0.906)$ & 0.268 & $(0.998)$ \\
\hline$c 2$ & $2.176^{* * *}$ & $(0.770)$ & $1.912^{* *}$ & $(0.829)$ & 0.658 & $(1.019)$ & $2.775 * * *$ & $(0.746)$ & $2.256^{* * *}$ & $(0.810)$ & 0.688 & $(0.997)$ \\
\hline c3 & $2.540^{* * *}$ & $(0.789)$ & $1.988^{* *}$ & $(0.827)$ & 1.413 & $(1.014)$ & $3.258 * * *$ & $(0.781)$ & $2.340^{* * *}$ & $(0.810)$ & 1.460 & $(1.020)$ \\
\hline$c 4$ & $2.963^{* * *}$ & $(0.805)$ & $2.493^{* * *}$ & $(0.861)$ & $1.918^{* *}$ & $(0.976)$ & $3.656 * * *$ & $(0.782)$ & $2.894^{* * *}$ & $(0.835)$ & $1.962 * *$ & $(0.954)$ \\
\hline$c 5$ & $3.441^{* * *}$ & $(0.805)$ & $3.073^{* * *}$ & $(0.915)$ & $2.654^{* * *}$ & $(0.975)$ & $3.966 * * *$ & $(0.807)$ & $3.513 * * *$ & $(0.899)$ & $2.595 * * *$ & $(0.995)$ \\
\hline Athrho & & & & & & & $1.853 * *$ & $(0.824)$ & $1.284 * * *$ & $(0.362)$ & $1.085 * * *$ & $(0.374)$ \\
\hline Number of observations & 104 & & 104 & & 104 & & 100 & & 100 & & 100 & \\
\hline Log-likelihood & $-21,319.648$ & & $-15,958.174$ & & $-22,695.161$ & & $-18,926.947$ & & $-17,940.517$ & & $-20,928.864$ & \\
\hline Pseudo $R^{2}$ & 0.1431 & & 0.2343 & & 0.1161 & & 0.107 & & 0.042 & & 0.081 & \\
\hline
\end{tabular}

The values between parentheses are the robust standard error corrected by the White method

Significance level: *10 \%; **5\%; **1 \% 
Table 6 equally shows that the (tic) variable has no considerable impact on innovation while concentration (concen) plainly affects the innovation activity. Indeed, the findings of this paper attest that introducing information technologies in a firm has no impact on reducing costs and production flexibility. On the other hand, it has a significant, but negative, impact on enhancing the quality of service. This result invalidates that of Gago and Rubalcaba (2007) who notice that introducing ICTs is propitious to innovation in services. Nevertheless, it can be said that service firms can introduce ICTs but that does not mean they can manage and valorize these ICTs to develop innovations (Omrane and Bouillon 2004).

As previously mentioned, it is shown that the concentration of firms (concen) positively affects the development of innovations. Actually, establishing a firm in a technology-intensive area (for instance the science parks) contributes to enhancing its new product/service development policy. Due to such favorable technological infrastructure, parks favor the creation and marketing of new products/services. According to this ascertainment, it would be better for service firms to get as close as possible to each other in order to take advantage from productivity and innovation returns. This proximity permits also to firms to reap extra employment opportunity. Consequently, firms become capable of adapting to frequent changes and to the evolution of their environment. Again, the coefficient linked to "the interaction with clients" variable (intclt) bears a positive sign. This implies that the variable intclt has a positive and statistically significant impact on the three dimensions of innovation. The result implies that using the online marketing strategy to meet clients' needs allows firms to reduce costs, improve the quality of their services and increase the flexibility of their productions.

\section{Conclusions}

This paper endeavored to analyze how the domestic outsourcing of service activities contributes to the development of innovations. To do so, a standard ordered probit model is, first, used to explain the relationship between outsourcing and innovation. Second, to account for the selection effect, an ordered probit model with selection is adopted. The findings of the two estimating models show that, in accordance with those of Glass and Saggi (2001) and Görg and Hanley (2011), outsourcing positively affects innovation by reducing costs, increasing flexibility and enhancing the quality of services. On the other hand, it is found that corporate concentration positively affects innovation. If a firm is situated in a competence-intensive environment that includes activities such as IT, R\&D, data management, architecture and engineering services, it is more likely to adapt to frequent changes and to the evolution of its environment. This advantageous technological infrastructure enables firms to access to the neighboring firms' experiences and competences. Therefore, service firms would better be established close by other ones to take advantage from productivity and innovation profits. Thus, if a firm is established in a given area, it can have a fairly good idea about the surrounding firms. It can, therefore, make a selection among the providers it will accommodate. Accordingly, it can manage all or part of their information system in order to concentrate on its own core task while benefitting from adaptation, flexibility and competitiveness vis-à-vis the market demands and needs.

\section{Endnotes}

${ }^{1}$ As there is emphasis on analyzing the impact of innovation in the services sector, the choice of the population was restricted to the firms that mainly provide value- 
added services: companies linked to ICT-based services according to the nomenclature published in 'The directory of ICT in Tunisia' that is edited by Symbols Media (2005), The Banks listed in the 'Tunisia's Professional Association of Banks and Financial Institutions (APTBEF)' and Insurance Companies that are listed in the 'Tunisian Federation of Insurance Companies (FTUSA)'.

${ }^{2} \mathrm{~A}$ French version of the questionnaire and a data collection are available upon request.

${ }^{3}$ National Institute of the Statistics (INS): distribution of companies by number of employees in 2007.

${ }^{4}$ For more details, see National Institute of the Statistics (INS): distribution of companies by activities.

${ }^{5}$ According to the CIS3, product (good or service) innovation is 'the market introduction of a new good or service or a significantly improved good or service with respect to its capabilities, such as improved software, user friendliness, components or subsystems. The innovation (new or improved) must be new to your enterprise, but it does not need to be new to your sector or market. It does not matter if the innovation was originally developed by your enterprise or by other enterprises'.

${ }^{6}$ Are considered qualified the percentage of the number of employees in the firm holding a high academic level (baccalaureate or more).

${ }^{7}$ For further details, see Greene (2003).

${ }^{8}$ De Luca and Perotti (2010) have developed a new opsel command on the STATA software. The opsel command uses a standard maximum likelihood (ML) approach to fit a parametric specification of the model where errors are assumed to follow a bivariate Gaussian distribution.

\section{Appendix 1}

Table 7 Distribution of firms by main activity

\begin{tabular}{|c|c|c|c|c|c|c|}
\hline \multirow[t]{2}{*}{ Industry } & \multicolumn{2}{|c|}{ Total of firms } & \multicolumn{2}{|c|}{ Innovative firms } & \multicolumn{2}{|c|}{ Outsourcing firms } \\
\hline & Number & $\%$ & Number & $\%$ & Number & $\%$ \\
\hline ACT1 & 16 & 14.81 & 9 & 10.71 & 15 & 16.30 \\
\hline ACT2 & 35 & 32.41 & 24 & 28.57 & 32 & 34.78 \\
\hline АСТ3 & 57 & 52.78 & 51 & 60.71 & 45 & 48.91 \\
\hline Total & 108 & 100 & 84 & 100 & 92 & 100 \\
\hline
\end{tabular}

\section{Abbreviations}

CIS: Community Innovation Survey; ICT: information and communication technologies; KMO: Kaiser-Meyer-Olkin; MCA: multiple correspondence analysis is conducted; PCA: principal components analysis; R\&D: research and development; VIF: variance inflation factor.

Authors' contribution

The authors contributed equally to this work. All authors read and approved the final manuscript. her Ph.D from the same University. Her core research interests include Innovation analyses, Applied Econometrics and Environmental Economics.

Mohamed AYADI is currently a Professor of Econometrics and Quantitative Economics at the University of Tunis_Higher Institute of Management. He received his Ph.D in Mathematical Economics and Econometrics from the University of Toulouse, France. His core research interests include Innovation and New Products Analyses, Welfare and Poverty Analysis and Consumer Behavior and Public Economic Policies. 


\section{Competing interests}

The authors declare that they have no competing interests.

\section{Received: 2 December 2015 Accepted: 14 May 2016}

\section{Published online: 27 May 2016}

\section{References}

Akaike, H. (1974). A new look at the statistical model identification. Automatic Control, IEEE Transactions on, 19(6), 716-723.

Bartel, A, S. Lach, N. Sicherman, et C. for Economic Policy Research (Great Britain) (2008). Outsourcing and technological innovations: a firm-level analysis. Centre for Economic Policy Research.

Cantone, L, et P. Testa (2009). The outsourcing of innovation activities in supply chains with high-intensity of research and development. Esperienze d'Impresa 2, 199-221.

Carson, S. (2007). When to give up control of outsourced new product development. Journal of Marketing, 71(1), 49-66.

Caudy, D. (2001). Using R\&D outsourcing as a competitive tool. Medical Device and Diagnostic Industry, 23(3), $115-126$.

Cohen, W, et D. Levinthal (1990). Absorptive capacity: a new perspective on learning and innovation. Administrative science quarterly, 35(1), 128-152.

Cusmano, L., Mancusi, M., \& Morrison, A. (2009). Innovation and the geographical and organizational dimensions of outsourcing: evidence from Italian firm-level data. Structural Change and Economic Dynamics, 20(3), 183-195.

De Luca, G. et V. Perotti (2010). Estimation of ordered response models with sample selection. CElS Working Paper No. 168

Domberger, S. (1998). The contracting organization: a strategic guide to outsourcing. USA: Oxford University Press.

Ehie, I. (2001). Determinants of success in manufacturing outsourcing decisions: a survey study. Production and Inventory Management Journal, 42(1), 31-39.

Engardio, P., \& Arndt, M. (2006). The future of outsourcing. Business Week, 30, $50-64$.

Espino-Rodríguez, T., \& Padrón-Robaina, V. (2004). Outsourcing and its impact on operational objectives and performance: a study of hotels in the Canary Islands. International Journal of Hospitality Management, 23(3), 287-306.

Gago, D., \& Rubalcaba, L. (2007). Innovation and ict in service firms: towards a multidimensional approach for impact assessment. Journal of Evolutionary Economics, 17(1), 25-44.

Gallouj, F., \& Windrum, P. (2009). Services and services innovation. Journal of Evolutionary Economics, 19(2), 141-148.

Gilley, K., \& Rasheed, A. (2000). Making more by doing less: an analysis of outsourcing and its effects on firm performance. Journal of management, 26(4), 763-790.

Girma, S., \& Görg, H. (2004). Outsourcing, foreign ownership, and productivity: evidence from UK establishment-level data. Review of International Economics, 12(5), 817-832.

Glass, A., \& Saggi, K. (2001). Innovation and wage effects of international outsourcing. European Economic Review, $45(1), 67-86$

Görg, H., \& Hanley, A. (2011). Services outsourcing and innovation: an empirical investigation. Economic Inquiry, 49(2), $321-333$.

Greene.W.H. Econometric analysis. Fifth Edition, Prentice Hall, 2003.

Heckman, J. (1979). Sample selection bias as a specification error». Econometrica. Journal of the econometric society, 47(1).153-161.

Huang, Y., Chung, H., \& Lin, C. (2009). R\&D sourcing strategies: determinants and consequences. Technovation, 29(3), 155-169.

Kremic, T., Tukel, O., \& Rom, W. (2006). Outsourcing decision support: a survey of benefits, risks, and decision factors. Supply Chain Management: An International Journal, 11(6), 467-482.

Lankford, W., \& Parsa, F. (1999). Outsourcing: a primer. Management Decision, 37(4), 310-316.

Mairesse, J. et P. Mohnen (2003). R\&D and productivity: a reexamination in light of the innovation surveys. Dans DRUID Summer Conference, pp. 12-14.

Maskell, P., Pedersen, T., Petersen, B., \& Dick-Nielsen, J. (2007). Learning paths to offshore outsourcing: from cost reduction to knowledge seeking. Industry \& Innovation, 14(3), 239-257.

Miozzo, M., \& Soete, L. (2001). Internationalization of services: a technological perspective. Technological Forecasting and Social Change, 67(2-3), 159-185.

OCDE. (2005). Manuel d'Oslo : principes directeurs pour le recueil et l'interprétation des données sur l'innovation (OCDE).

Omrane, D. et J. Bouillon (2004). Tic et relations de services dans une économie globalisée. Rapport francophone, LERASS-Université Paul Sabatier Toulouse 3.

Pierre-Paul, P. (2006). L'externalisation de la production de biens et services : contexte, définition et effets économiques sur le pays d'origine et d'accueil (Chaier de recherche- CEIM).

Quinn, J. (2000). Outsourcing innovation: the new engine of growth. Sloan management review, 41(4), 13-28.

Schniederjans, M, Schniederjans, A, Schniederjans, D. (2005). Outsourcing and insourcing in an international context. ME Sharpe Inc. Routledge; New Ed (30 Septembre 2005).

Schwarz, G. (1978). «Estimating the dimension of a model». The annals of statistics, 6(2), 461-464.

Sdiri, H., \& Ayadi, M. (2014). Innovation decision of Tunisian service firms: an empirical analysis, Working Papers 2014-092 (Department of Research, Ipag Business School).

Uzunidis, D. (2010). Milieu innovateur, relations de proximité et entrepreneuriat. Analyse d'une alchimie féconde. Revue Canadienne de Science Régionale, 33, 91-106.

Windrum, P., Reinstaller, A., \& Bull, C. (2009). The outsourcing productivity paradox: total outsourcing, firmal innovation, and long run productivity growth. Journal of evolutionary economics, 19(2), 197-229.

Young, E. (2006). Baromètre outsourcing 2006: Pratiques et tendances de l'externalisation en Tunisie (Andersen).

Young, E. (2010). Baromètre Outsourcing 2010: Pratiques et tendances du marché de l'externalisation en France. Paris: Andersen. 